\title{
Comparativa del estado actual de los focos de Seca inventariados entre 2003 y 2004, en masas de Quercus de Extremadura
}

\author{
Manzano M.J. ${ }^{*}$, Belvis G. ${ }^{1}$, Folgueiras R. ${ }^{1}$, Prieto J.M. ${ }^{1}$ \\ ${ }^{1}$ Estudios Medioambientales S.L. (ESMA). C/ Hoyuelo $n^{\circ} 3$ 28007. Madrid
}

*Autor para correspondencia: mjmanzano@esmasl.es

\section{Resumen}

Entre los años 2003 y 2004 se realizó un inventario piloto en zonas afectadas por la Seca de los Quercus en Extremadura, obteniendo una metodología para la prospección y seguimiento de los focos de Seca.

Ante la preocupación continuada por el grave decaimiento de las dehesas extremeñas, causado por la Seca; el Servicio de Ordenación y Gestión Forestal de la Junta de Extremadura decide realizar un nuevo estudio, denominado "Prospección y Seguimiento de masas de Quercus afectadas por Seca en la Comunidad Autónoma de Extremadura".

Este trabajo ha permitido, entre otras cuestiones, conocer el estado actual de los focos de Seca que fueron prospectados en el primer estudio. De este modo se realiza una comparación del estado que presenta el arbolado, frente a lo observado en las visitas de 2003 (Cáceres) y 2004 (Badajoz).

Los resultados obtenidos contribuyen a conocer mejor este complejo proceso de decaimiento de las dehesas, lo que permite planificar una gestión adecuada en las masas forestales afectadas.

Palabras clave: Decaimiento, dehesa, evolución, foco de Seca. 


\section{Introducción}

A principios de la década de los 80 del siglo pasado comenzó a observarse un acusado deterioro del estado sanitario en masas de encinas (Quercus ilex) y alcornoques (Quercus suber) del sudoeste peninsular, según la distribución de las dehesas de la Península Ibérica (Blanco et al., 2005); si bien los daños observados no resultaron alarmantes hasta finales de los años 80 y primeros de los 90 .

Este proceso, denominado decaimiento de los Quercus, más conocido como Seca, está ocasionando la pérdida de numerosos ejemplares, suponiendo una grave amenaza medioambiental, que origina pérdidas económicas en los sistemas adehesados (Tuset, 2004). Por tanto, es de vital importancia continuar conociendo su comportamiento ante una serie de factores comunes.

Durante los años 2003 y 2004 la Junta de Extremadura encargó un primer inventario de zonas afectadas por Seca, estos trabajos denominados "Desarrollo y Metodología para la realización de un inventario piloto en zonas afectadas por la Seca de quercíneas (Cáceres)"; (ESMA S.L., 2003) y “Metodología para la prospección y el seguimiento de masas de quercíneas afectadas por la Seca en la provincia de Badajoz"; (ESMA S.L., 2004).

De ellos se obtuvo, además de una metodología para la prospección, seguimiento y caracterización de las masas afectadas; unos resultados concluyentes sobre la situación de las zonas de Quercus prospectadas en ese momento.

Transcurridos 12 años de esa primera prospección, el Servicio de Ordenación y Gestión Forestal de la Junta de Extremadura decide realizar un nuevo estudio, denominado "Prospección y Seguimiento de masas de Quercus afectadas por Seca en la Comunidad Autónoma de Extremadura" (ESMA S.L., 2015); que permita conocer, entre otras cuestiones, el estado actual de los focos de Seca localizados en masas adehesadas del género Quercus que fueron identificados en 2003 y 2004.

\section{Objetivos}

Utilizando el Mapa de Paisajes de Extremadura, basado en el tercer Inventario Forestal Nacional se realiza, entre otras actuaciones, una nueva prospección de las masas de Quercus visitadas entre 2003 y 2004. Para ello se utiliza la metodología obtenida en el inventario inicial, incorporando nuevas variables significativas para este nuevo trabajo.

En estas zonas se observa la evolución del estado del arbolado y cómo ha influido la aplicación de tratamientos culturales y preventivos en la propagación del decaimiento del arbolado.

El análisis de los resultados obtenidos, permitirá conocer la influencia que tienen ciertas variables en el decaimiento del arbolado con el fin de establecer conclusiones y realizar las propuestas más adecuadas, para cada una de las zonas afectadas en las diferentes regiones de la Comunidad. 


\section{Metodología}

La Consejería de Medio Ambiente y Rural, Políticas Agrarias y Territorio, a través del Servicio de Ordenación y Gestión Forestal facilita los diferentes datos de las zonas o fincas afectadas por Seca, en el trabajo desarrollado entre 2003 y 2004.

Para conocer la evolución del arbolado existente en los focos incluidos en ambos trabajos, se hace imprescindible volver a visitar los 440 focos que fueron objeto de estudio. En su caracterización se emplea la misma metodología que fue utilizada en 2003 y 2004; si bien se incluyen nuevas variables que se han considerado relevantes (presencia de hongos lignívoros de pudrición, cerambícidos, balsas de agua próximas, tipo de ganado presente...), para la obtención de nuevos resultados.

Por otra parte, la diferencia principal entre ambos estudios radica en que en 2015 se ha trazado un polígono digital, utilizando el software QGIS 2.6 y ortofotografías del PNOA, para limitar el foco de Seca; mientras que en el estudio de 20032004 se realizaba una estimación visual de la superficie afectada.

Tras las labores previas de comunicación y con la colaboración de las Unidades Territoriales de Vigilancia (UTV), dependientes de la Consejería, comienzan las visitas de campo.

Cada equipo de campo procede a la localización y acceso al foco de Seca objeto de la visita; mediante un vehículo todo terreno equipado con un equipo informático. Se utiliza un sistema específico propio de localización y replanteo en campo,

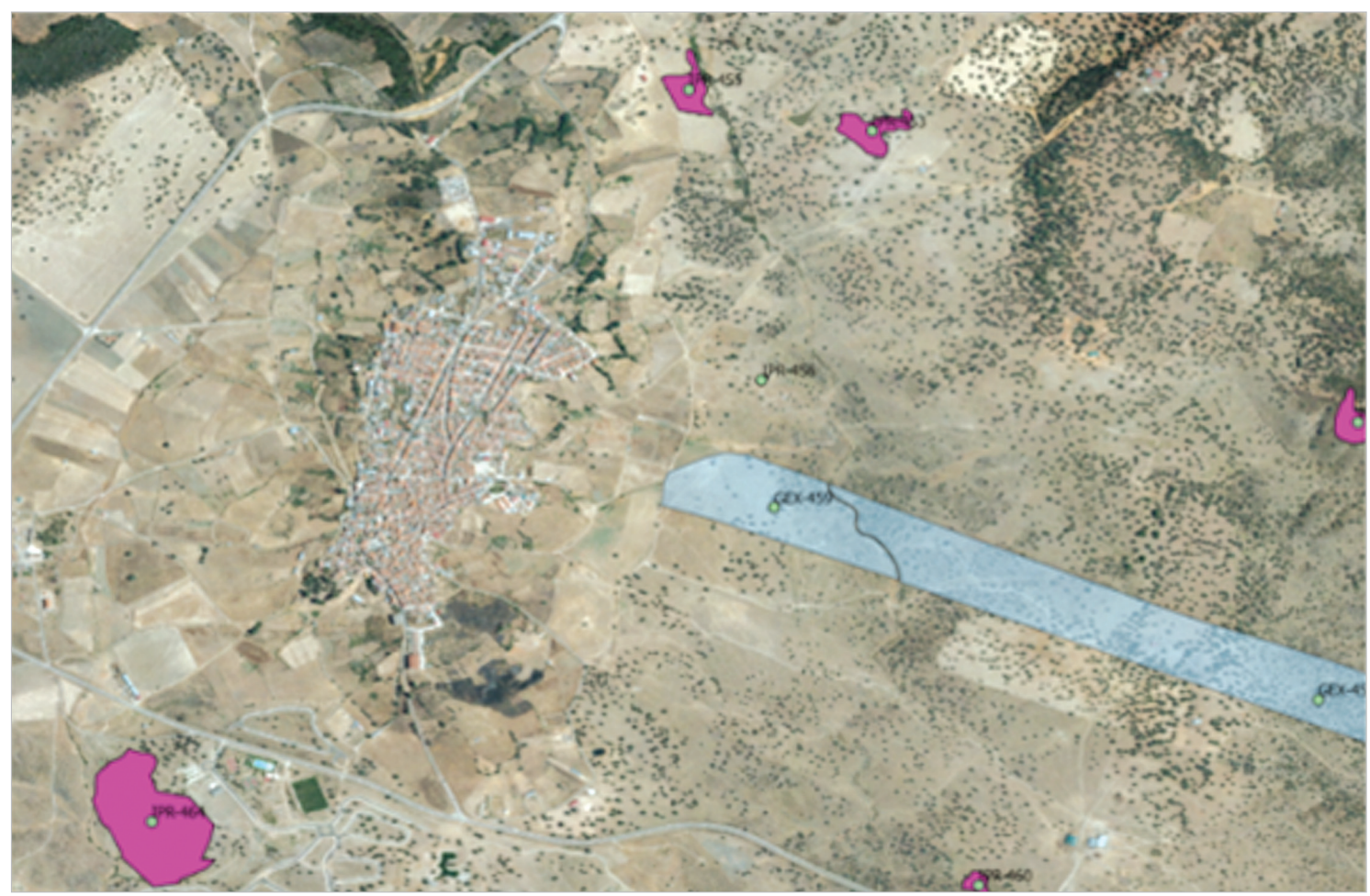

Figura 1. Situación de áreas afectadas por Seca en el entorno de Castilblanco (Badajoz). 
basado en la personalización de un software de navegación y la implementación en un ordenador portátil con receptor GPS, de un proyecto con ortofotografías de alta resolución y localización en tiempo real (Fig. 1).

Para la localización del foco, se parte de las coordenadas de campo tomadas en el estudio anterior, cargadas en un proyecto de QGIS 2.6.

Además, se graba un track del recorrido realizado, durante el acceso, que queda archivado y etiquetado de manera independiente.

Sobre el terreno se recorre la zona afectada en su totalidad, para detectar las áreas más afectadas, que conforman el foco. A continuación, se procede a su caracterización cumplimentando la ficha correspondiente, se toman las coordenadas GPS (Fig. 2) y se realizan fotografías tanto panorámicas, como específicas de daños, si procede.

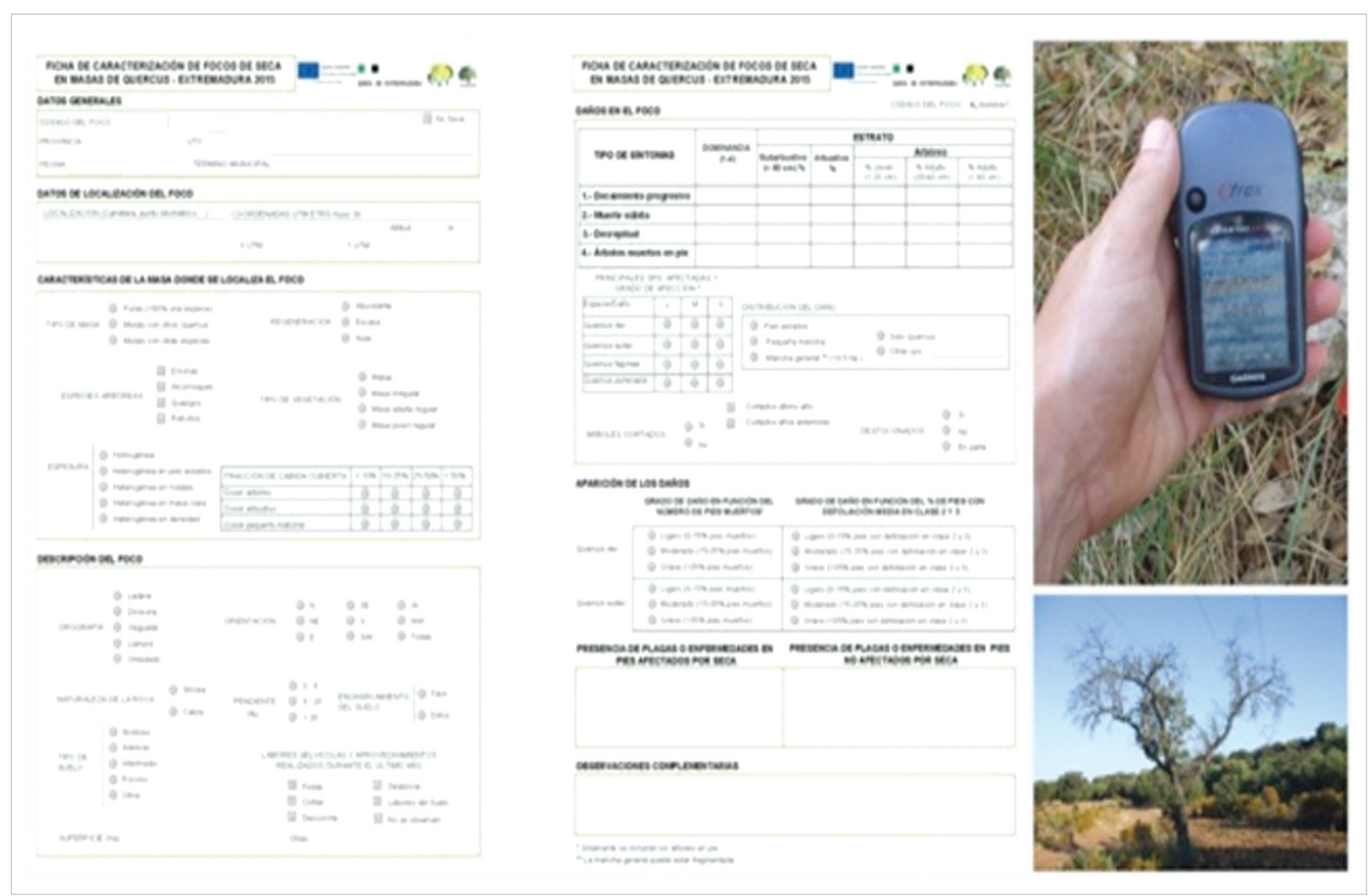

Figura 2. Ficha, imagen y toma de coordenadas de un foco.

Una vez caracterizado el foco, se procede in situ a su delimitación digital (Fig. 3). El polígono, en formato "shape" de ESRI, queda definido por la presencia continua sobre el terreno de pies aparentemente sanos; o por la existencia de modificaciones del terreno que impidan el avance del mismo (transición en el uso del suelo de forestal a agrícola o improductivo, transición a masas forestales pobladas por especies no susceptibles de padecer Seca, etc.).

Así, la información obtenida en campo para cada foco, queda recogida de cinco formas: 


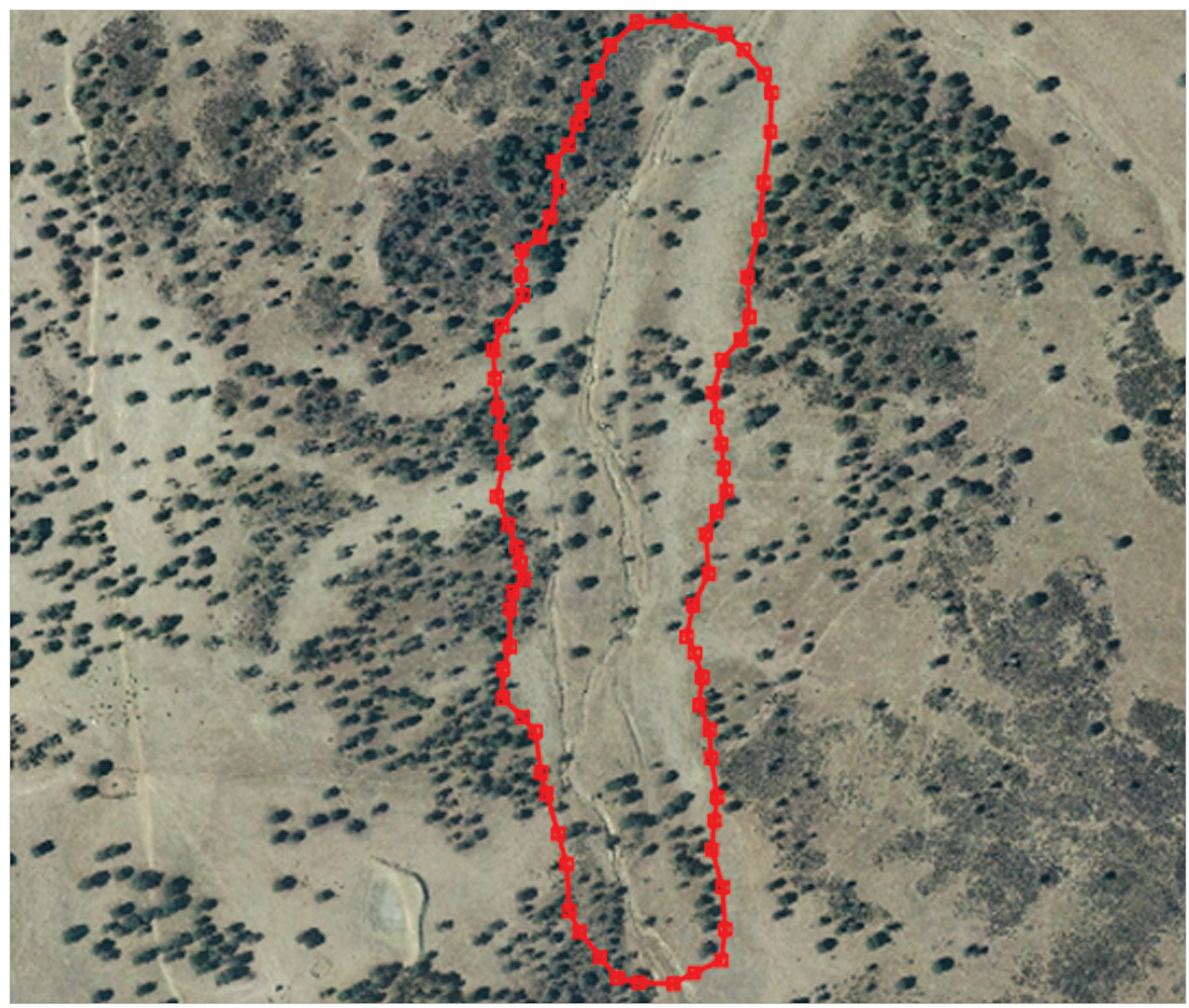

Figura 3. Delimitación de un foco de Seca.

- Ficha de caracterización.

- Track de acceso.

- Coordenadas.

- Fotografías.

— Delimitación en formato digital.

\section{Resultados}

En gabinete se procesan los datos de campo y se someten a análisis geoestadísticos. Se compara el estado que presentan los focos de Seca caracterizados entre 2003 y 2004 en el estudio "Prospección y seguimiento de masas de Quercus afectadas por Seca en las provincias de Cáceres y Badajoz"; con lo observado en la actualidad.

Hace 12 años se visitaron y prospectaron 440 focos, de los que 241 corresponden a la provincia de Cáceres y 199 a la de Badajoz (Fig. 4). 


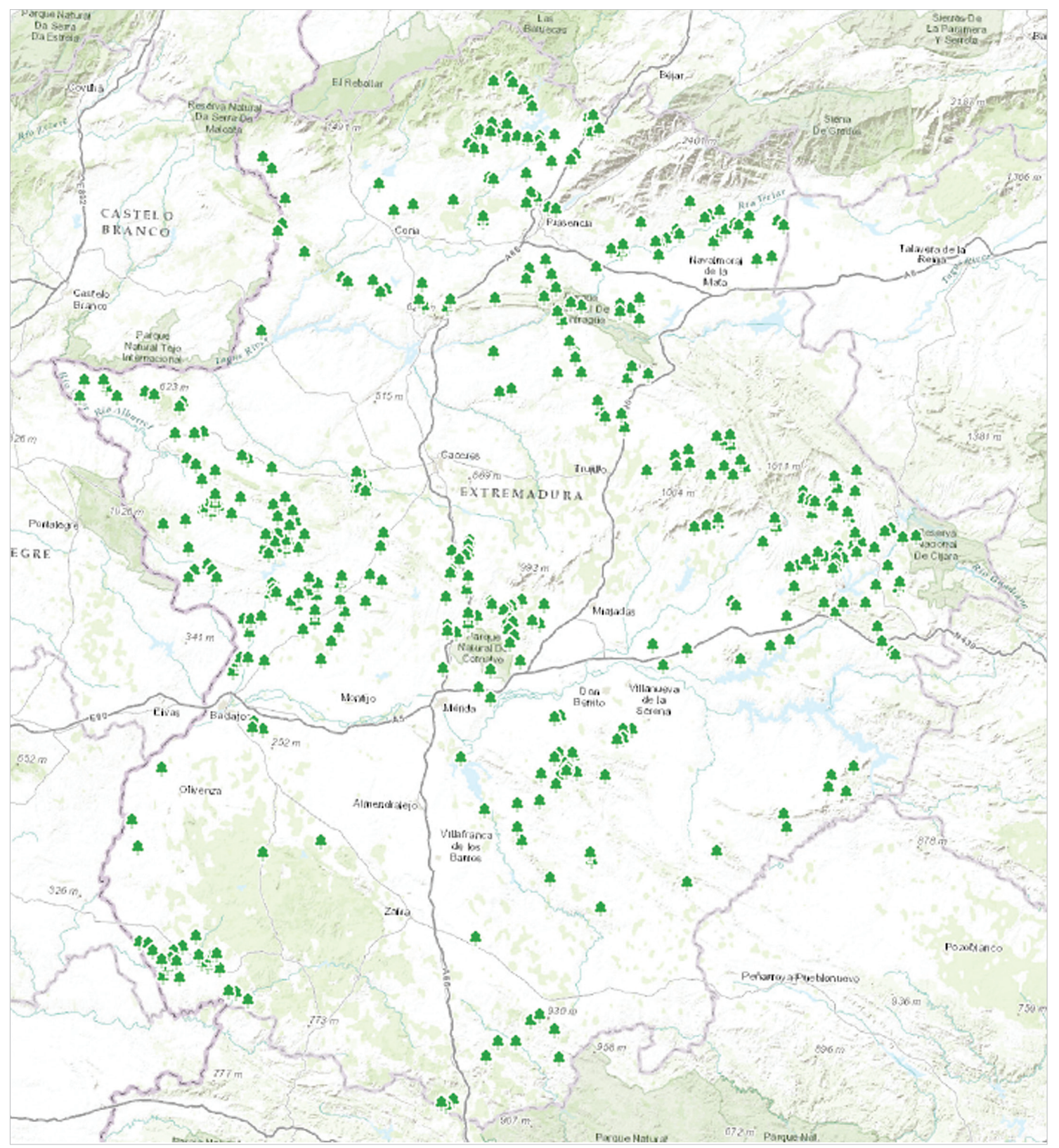

Figura 4. Mapa de situación de los focos visitados.

En 2015 se han visitado 434 focos, ya que 6 de ellos han resultado inaccesibles (4 en Badajoz y 2 en Cáceres) y por tanto, no se tienen en cuenta en el estudio de evolución. Se han observado daños en 381 de ellos; lo que supone una disminución del $12,21 \%$ en la cantidad de focos con sintomatología asociada a Seca, respecto al estudio de 2003-2004 (Tab. 1).

El hecho de no encontrar daños por Seca, se debe a que en estos focos se ha constatado la corta de los ejemplares afectados, entre 2003-2015. En estas localizaciones no se ha observado nuevo arbolado afectado. 
Tabla 1. Evolución de la distribución de focos con presencia de daños compatibles con Seca.

\begin{tabular}{lcccc}
\hline & \multicolumn{2}{c}{2003} & \multicolumn{2}{c}{2015} \\
\hline \hline $\begin{array}{c}\text { Puntos con presencia } \\
\text { de Seca }\end{array}$ & $\begin{array}{c}\text { Puntos sin presencia } \\
\text { de Seca }\end{array}$ & $\begin{array}{c}\text { Puntos con presencia } \\
\text { de Seca }\end{array}$ & $\begin{array}{c}\text { Puntos sin presencia } \\
\text { de Seca }\end{array}$ \\
\hline $\mathrm{N}$ & 440 & 0 & 381 & 53 \\
\hline$\%$ & $100,00 \%$ & $0,00 \%$ & $87,79 \%$ & $12,21 \%$ \\
\hline
\end{tabular}

Atendiendo a las Características del Foco de Seca, se ha observado lo siguiente:

- En más del 90\% de los focos no se han realizado ni podas ni cortas, durante el último año; lo cual también ocurrió en 2003-2004.

- En el 71,7\% de los focos que en 2015 no presentan pies afectados por Seca; se ha comprobado la corta de árboles, durante estos años.

- En la actualidad, la regeneración es escasa en el 35,6\% de los focos de Seca y nula en el $27,4 \%$.

- Respecto a 2004 los focos que presentan una regeneración escasa han aumentado un 2,8\%; mientras que aquellos en los que es nula, han aumentado un $0,4 \%$.

- En el 54,8\% de los focos que presentan regeneración escasa/nula y en el 3,7\% en los que es abundante, hay presencia de ganado.

- En 2015, la cantidad de focos que presentan árboles afectados por hongos lignívoros de pudrición y/o cerambícidos es del 43,2\% cuando aparecen daños por Seca; frente a un $17,4 \%$ en caso de no detectar sintomatología asociada a Seca.

- Las variables cortas, podas, laboreo del suelo y regeneración no muestran ninguna relación con la presencia visual de daños por Seca.

- La espesura y la fracción de cabida cubierta son variables que sí parecen estar relacionadas con la presencia de daños por Seca, de manera que los focos con fcc $<10 \%$ han aumentado un $8 \%$, respecto a $2003-2004$.

A la hora de analizar los daños presentes en el foco de Seca, se evalúa el Grado de Afección (ligero, moderado y grave); diferenciando entre encinas (Fig. 5) y alcornoques (Fig. 6). Esto permite analizar por separado, el comportamiento de ambas especies frente a la Seca. 


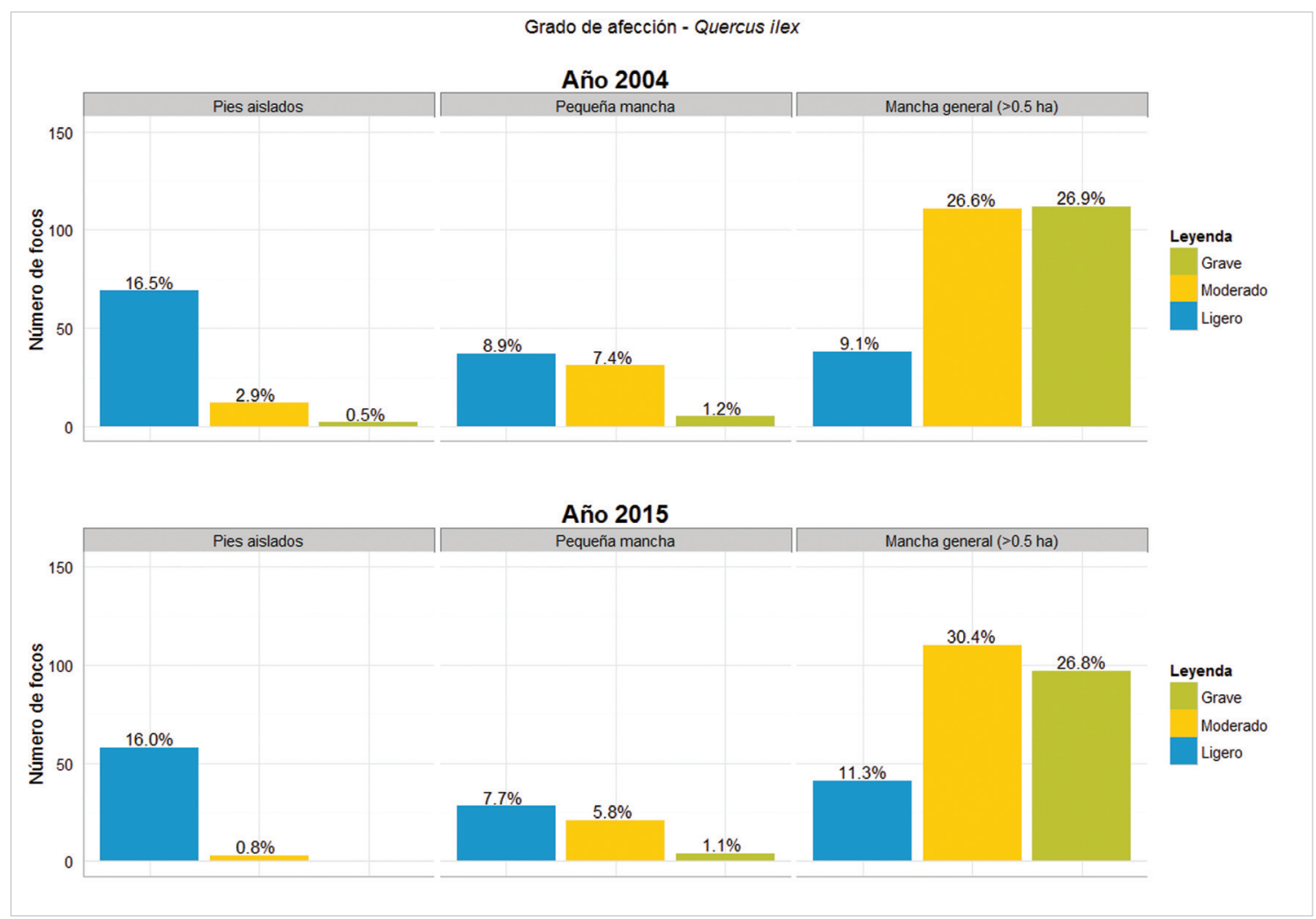

Figura 5. Comparación del Grado de Afección de encinas en focos de Seca de Extremadura.

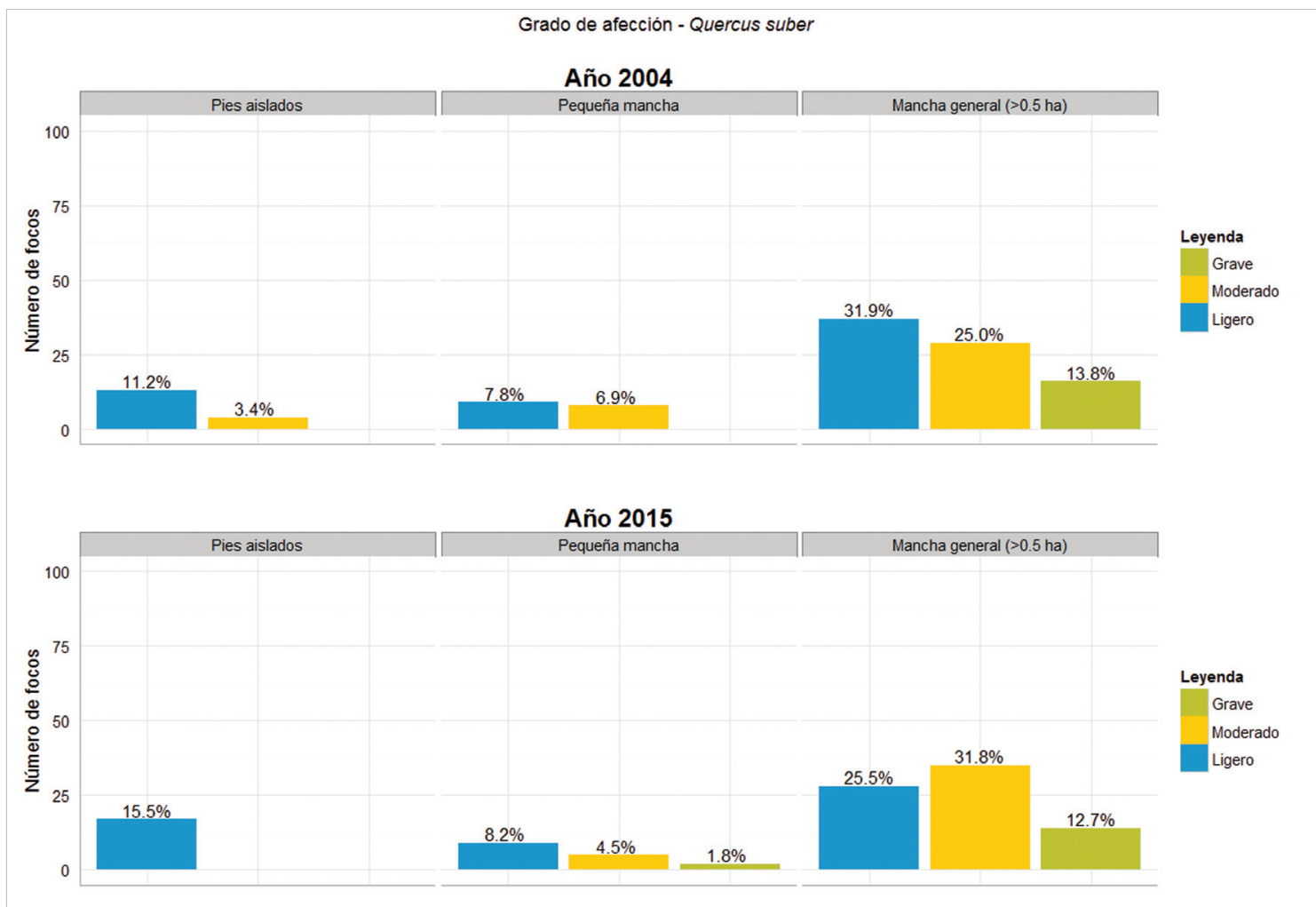

Figura 6. Comparación del Grado de Afección de alcornoques en focos de Seca de Extremadura. 
- Se ha confirmado la tendencia de 2004, en la que se observaba un grado de afección moderado en las encinas.

- La cantidad de focos de encina que presentan afecciones moderadas y graves ha disminuido un 0,21 y un $0,5 \%$ respectivamente.

- En ambos periodos de estudio predominan los focos de Seca de encina, denominados mancha general, que han aumentado un 5,9\% respecto a 2004 .

- Los grados de afección moderado y grave son los que predominan en los focos de encina de mayor superficie; tanto en 2004 (53,5\%), como en 2015 (57,2\%).

- Se ha confirmado la tendencia de 2004, en la que se observaba un grado de afección ligero en los alcornoques.

- La cantidad de focos de alcornoque que presentan afecciones moderadas y graves ha aumentado un 1,4 y un $0,8 \%$ respectivamente.

- En ambos periodos de estudio predominan los focos de Seca, de alcornoque, denominados mancha general, que han disminuido un $0,7 \%$, respecto a 2004.

- El grado de afección ligero predomina en los focos de alcornoque de mayor superficie en 2004 (31,9\%); mientras en 2015 predomina el grado moderado $(31,8 \%)$.

Para estudiar el modo en que aparecen los daños en los focos de Seca, se observa la cantidad de árboles muertos en pie y el grado de defoliación que presentan los ejemplares afectados; distinguiendo entre encinas (Fig. 7) y alcornoques (Fig. 8).

El Grado de Daño en función del Número de Pies Muertos, se clasifica como ligero $(0-15 \%$ de pies muertos), moderado $(15-35 \%$ de pies muertos) y grave $(>35 \%$ de pies muertos).

- En los focos grandes de encina, hay mayor porcentaje de ejemplares muertos, frente a los pequeños.

- En los focos grandes de encina, los daños moderados han disminuido un $16,4 \%$.

— En los focos grandes de encina, los daños ligeros han aumentado un 22,4\%.

- En manchas pequeñas de encina $(<0,5 \mathrm{ha})$, los daños moderados han disminuido un $5,2 \%$. 


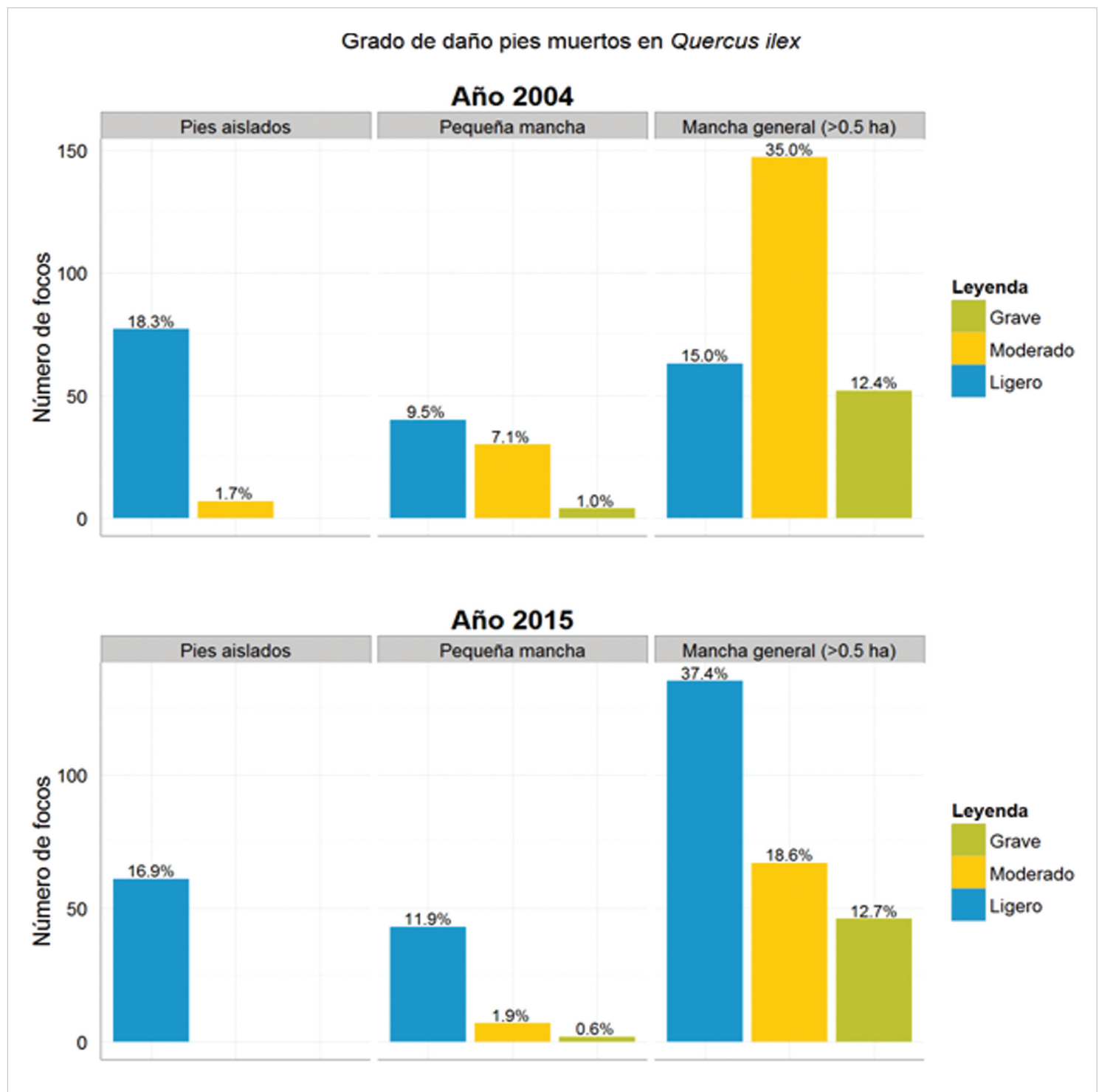

Figura 7. Comparación del Grado de Daño en función del Número de encinas muertas en focos de Seca de Extremadura.

- En manchas pequeñas de encina $(<0,5$ ha), los daños ligeros han aumentado un $2,4 \%$.

- En encinas aisladas los daños ligeros han disminuido un 1,9\% y los moderados han desaparecido.

- En los focos grandes de alcornoque, hay mayor \% de ejemplares muertos, frente a los pequeños.

- En los focos grandes de alcornoque, los daños moderados han disminuido un $10,6 \%$. 


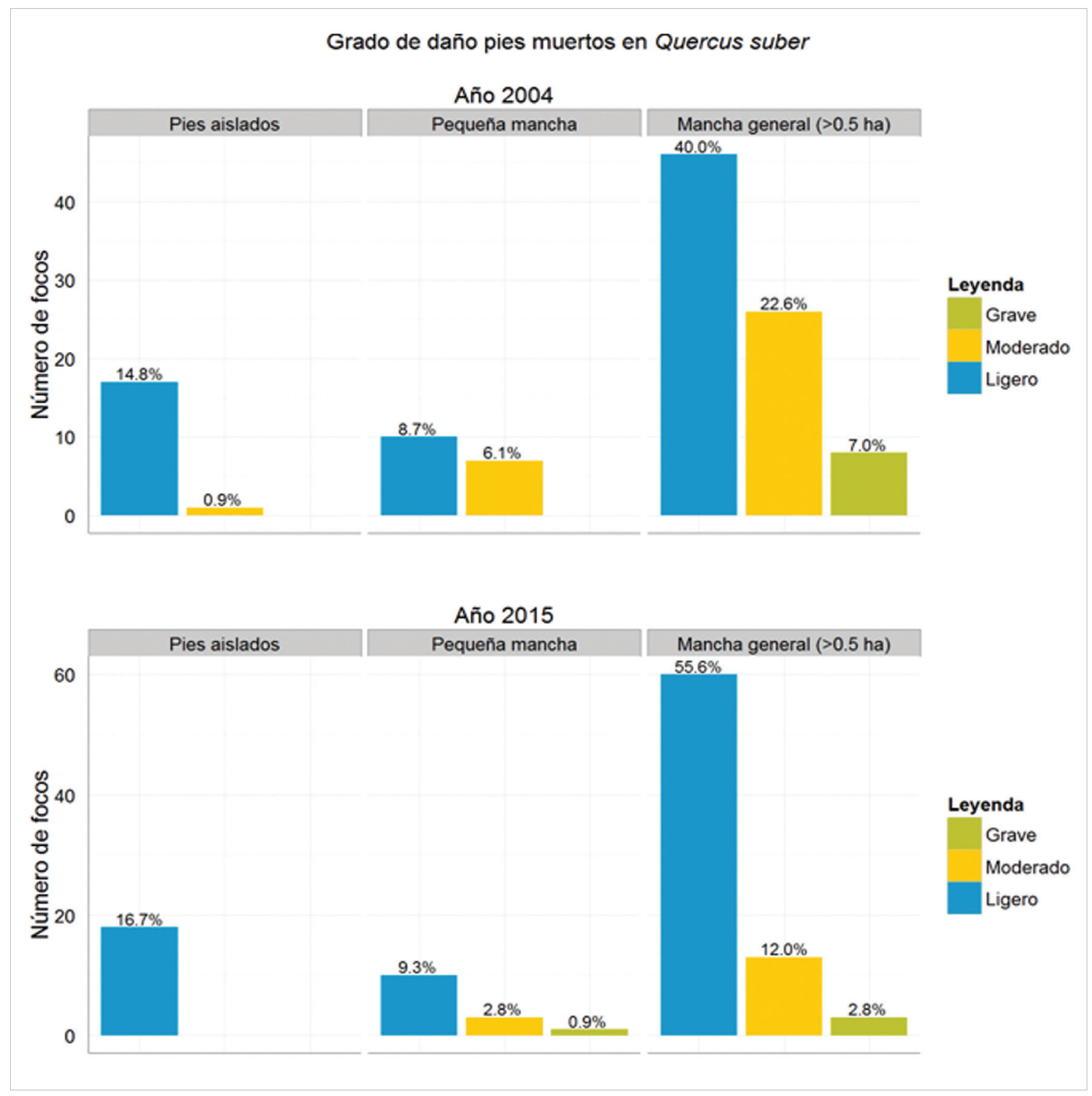

Figura 8. Comparación del Grado de Daño en función del Número de alcornoques muertos en focos de Seca de Extremadura.

- En los focos grandes de alcornoque, los daños ligeros han aumentado un $15,6 \%$.

- En manchas pequeñas de alcornoque $(<0,5 \mathrm{ha})$, los daños moderados han disminuido un $3,3 \%$.

- En manchas pequeñas de alcornoque $(<0,5 \mathrm{ha})$, los daños graves han aumentado un $0,9 \%$.

- En alcornoques aislados los daños moderados han disminuido un $0,9 \%$ y han desaparecido. 
Evaluando el Grado de Daño en función del \% de defoliación en clase 2 (del 26 al $64 \%$ de defoliación) y 3 (del 65 al 99\% de defoliación); se establecen 3 grados: ligero $(0-15 \%$ de pies con defoliación en clase 2 y 3$)$, moderado ( $15-35 \%$ de pies con defoliación en clase 2 y 3 ) y grave (>35\% de pies con defoliación clase 2 y 3 ). Para ello, se entiende la defoliación como la pérdida prematura de hojas de encina (Fig. 9) y alcornoque (Fig. 10), a causa de la afección de agentes de origen biótico o abiótico.

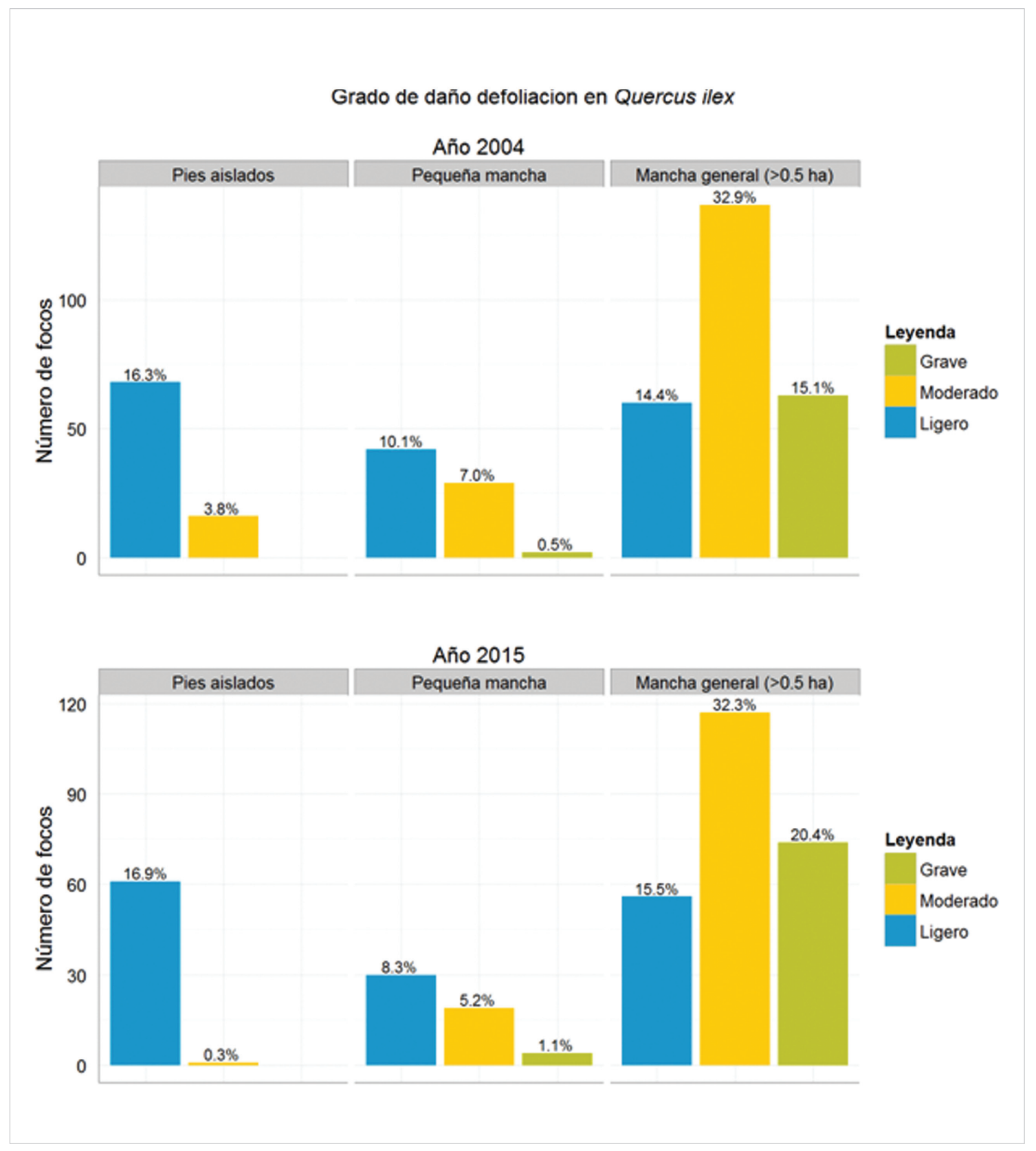

Figura 9. Comparación del Grado de Daño en función del \% de Defoliación de encinas en clase 2 (del 26 al 64\% de defoliación) y 3 (del 65 al 99\% de defoliación) en focos de Seca de Extremadura. 
- La cantidad de focos de encina de gran tamaño, ha aumentado un 5,8\%.

- La cantidad de focos de encina de gran tamaño, calificados como ligeros ha aumentado un $1,1 \%$.

- La cantidad de focos de encina calificados como graves, ha aumentado un $5,9 \%$.

- La cantidad de focos de alcornoque calificados como ligeros ha disminuido un $21 \%$.

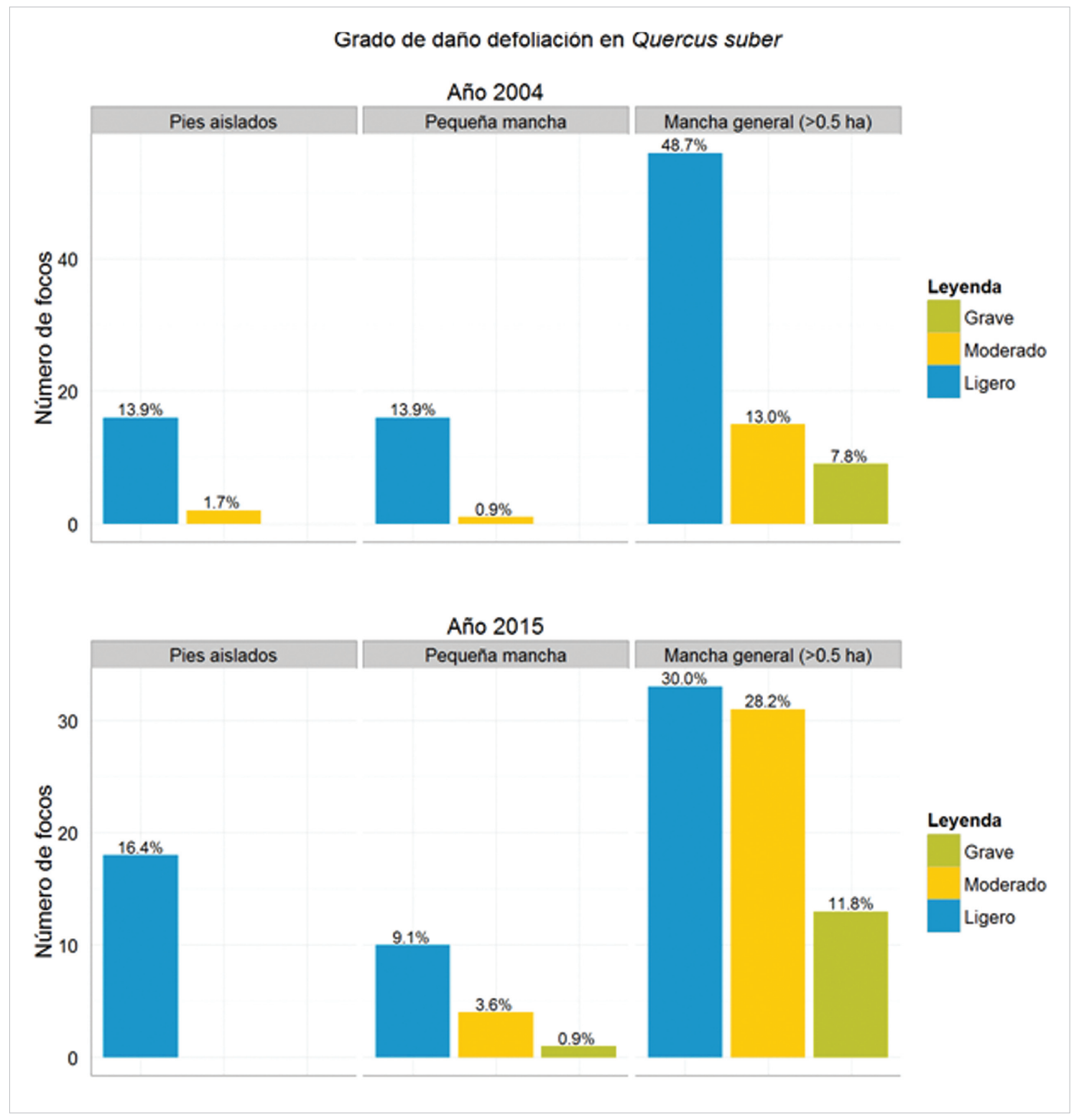

Figura 10. Comparación del Grado de Daño en función del \% de Defoliación de alcornoques en clase 2 (del 26 al 64\% de defoliación) y 3 (del 65 al 99\% de defoliación) en focos de Seca de Extremadura. 
- La cantidad de focos de alcornoque calificados como moderados ha aumentado un $16,2 \%$.

- La cantidad de focos de alcornoque calificados como graves ha aumentado un $4,9 \%$.

- La cantidad de focos de alcornoque de pequeño tamaño $(<0,5$ ha $)$, calificados como moderados han aumentado un $2,7 \%$.

- La cantidad de focos de alcornoque de pequeño tamaño $(<0,5$ ha $)$, calificados como graves ha aumentado un $0,9 \%$.

\section{Discusión y Conclusiones}

En 2015 no se ha detectado sintomatología atribuible a Seca en el 12,21\% de los focos visitados entre 2003 y 2004; ya que se han retirado los pies afectados y no han aparecido nuevos casos.

En función de los resultados observados, la retirada de pies secos en los focos afectados por Seca, parece resultar beneficiosa para ralentizar su avance.

Durante el periodo de estudio, se ha observado un aumento de la cantidad de focos de Seca que presentan superficie superior a 1 ha; mientras que los pequeños $(<0,5 \mathrm{ha})$ y los formados por algunos ejemplares aislados muestran una tendencia descendente.

Al analizar el nivel de daño, considerado en función del porcentaje de pies muertos, se percibe un incremento de los daños moderados (de 15 al 35\% de pies muertos) en detrimento de los daños ligeros ( $<15 \%$ de los pies muertos). Esto podría estar relacionado, por una parte con la afección de los patógenos implicados en el decaimiento del arbolado y por otra, con la corta de los ejemplares afectados; esto último ligado a la gestión de la masa por parte de la propiedad.

Otra forma de determinar el nivel de daño es mediante la evaluación de la pérdida de superficie foliar o defoliación. En este caso, se ha observado un comportamiento distinto entre encinas y alcornoques. La primera especie ha mostrado unos niveles de defoliación similares a los observados durante los años 2003 y 2004. El alcornoque, en cambio, ha mostrado un incremento de los daños moderados (15-35\% de pies con defoliación en clase 2 y 3 ) y grave ( $>35 \%$ de pies con defoliación en clase 2 y 3 ).

Si bien la Seca de los Quercus es uno de los principales causantes del decaimiento del arbolado que forma parte de las dehesas de Extremadura (Lopes et al., 2014); existen otros agentes como son los hongos de pudrición y los insectos perforadores (cerambícidos), que influyen de forma grave en el estado del arbolado (Muñoz et al., 2003) y por tanto, es recomendable realizar estudios más concretos sobre ello.

El decaimiento de las dehesas de Quercus causado principalmente por la Seca 
es un fenómeno complejo que conviene conocer y estudiar en profundidad. La implicación del Oomycete Phytophthora cinnamomi (Rodríguez-Molina, et al., 2012) en este fenómeno está sobradamente demostrada y supone una línea de investigación de gran interés. El monitoreo continuo del estado del arbolado presente en los focos de Seca, podría resultar una herramienta muy útil desde el punto de vista científico y técnico de cara a la obtención de datos de origen diverso. Con ello, se lograrían diferentes objetivos, como por ejemplo, conocer la influencia que tiene la gestión realizada en los focos afectados. Resultaría, por tanto, interesante establecer una muestra fija de focos (Red de Focos de Seca), distribuidos de manera que representen características diversas, en cuanto a su gestión, fisiografía, edafología y climatología. En cada uno de los focos objeto de estudio, se analizarían las mismas variables durante las diferentes visitas, comprobando su influencia en el decaimiento del arbolado.

\section{Agradecimientos}

A la Consejería de Medio Ambiente y Rural, Políticas Agrarias y Territorio, que a través de José Luis del Pozo Barrón, Jefe del Servicio de Ordenación y Gestión Forestal, ha ejercido de promotor de este proyecto. También, a Beatriz Rocha Granado, Jefa de Sección de Recursos y Desarrollo Forestal y al técnico Jesús Gonzálvez de Miranda que ha facilitado toda la información necesaria y marcado las directrices para la correcta ejecución del trabajo.

Por último, reconocer la labor de los Agentes del Medio Natural y de los coordinadores de las Unidades Técnicas de Vigilancia (UTV), que han colaborado en todo lo que se ha demandado durante los trabajos de campo.

\section{Bibliografía}

Blanco, E., et al. 2005. Los bosques ibéricos. Una interpretación geobotánica. Planeta, Barcelona.

Lopes, A., et al. 2014. Presentaciones y conclusiones Foro INIA sobre la Seca. Centro de Investigaciones Científicas y Tecnológicas de Extremadura http://cicytex.gobex.es/presen taciones-foro-inia. Acceso: 8 de abril de 2015.

Muñoz, C., et al. 2003. Sanidad Forestal. Guía en imágenes de plagas, enfermedades y otros agentes presentes en los bosques. Mundi-Prensa, Madrid.

Rodríguez-Molina, M.C., Palo, E., Blanco, A., Torres-Vila, L.M., Santiago, R., Del Pozo, J., Colino, M.I., Torres, E., Suárez, M.A. 2012. Phytophthora cinnamomi: un Oomycete implicado en la Seca de encinas y alcornoques. Revista Phytoma. 236, 36-40. ISSN: 11318988.

Tuset, J.J., Sánchez, G. 2004. La Seca: El decaimiento de encinas, alcornoques y otros Quercus en España. Ministerio de Medio Ambiente. Organismo Autónomo Parques Nacionales, Madrid. 
